\title{
Preliminary Laser Cleaning Studies of a Consolidated Prehistoric Basketry Coming from the Pile Building of Fiavè-Carera in the North-East of Italy
}

\author{
Romina Belli, ${ }^{1}$ Antonio Miotello, ${ }^{1}$ Paolo Mosaner, ${ }^{1}$ Laura Toniutti, ${ }^{1}$ and Marta Bazzanella ${ }^{2}$ \\ ${ }^{1}$ Department of Physics, University of Trento, 38050 Povo, Trento, Italy \\ ${ }^{2}$ Museum of Usi e Costumi della Gente Trentina, 38010 San Michele all'Adige, Trento, Italy
}

Received 20 July 2006; Revised 6 November 2006; Accepted 30 November 2006

Recommended by Marta Castillejo

In the archaeological field, some specific advantages are recognized to laser cleaning, like, for example, the absence of mechanical contacts with the sample. The cleaning procedures generally involve a multilayer structure (dust, dirty, organic deposits, and, in some cases, consolidant substances). In this work, prehistoric wood samples (found and consolidated in 1970s) have been laser irradiated ( $\mathrm{KrF}$ excimer laser) in order to restore their original surface aspect. A certain amount of burned matter was also present. Samples came from a fragment of a prehistoric basketry found in the lake dwelling site of Fiavè-Carera, Trento, Italy (1500-1400 $\mathrm{BC}$ ). It was observed that the laser cleaning effects are strictly dependent on the irradiation parameters (power density and number of pulses). Efficient material removal was possible by using appropriate energy density. Moreover, for lower laser energy density, special structures appeared on the surface of the consolidating substance that we attributed to heating-induced stresses on the consolidant surface.

Copyright (c) 2006 Romina Belli et al. This is an open access article distributed under the Creative Commons Attribution License, which permits unrestricted use, distribution, and reproduction in any medium, provided the original work is properly cited.

\section{INTRODUCTION}

The present research activity belongs to a cooperation project between the Department of Physics of Trento University and the Museum "degli Usi e Costumi della Gente Trentina" of San Michele all'Adige (North-East Italy); new techniques are tested in preservation of cultural heritage.

A fragment of basketry (Figure 1), recovered from the prehistoric lake dwelling site of Fiavè-Carera (the site was excavated just in those years by archaeologist Renato Perini of Museo Tridentino of Scienze Naturali, (Trento, Italy)), entered the Museum's collections in 1970 (it was a gift from the Museo Tridentino di Scienze Naturali). Giuseppe Šebesta, founder of the institution, strongly wanted this particular find to be kept in this otherwise ethnographic museum, since he maintained that the presence of some archaeological materials in the exhibition could bring one back to the preand protohistoric origins of the material culture of local rural communities (at the beginning the Museum ground was organized in the so-called "closed channels," that is, separate technoeconomical contexts, each defined as "the way": the way of wood, the way of copper, the way of iron, the way of wool, the way of the mill, etc.). In the early 1990s, in the course of a full revision of the permanent exhibition, the specimen was moved to the museum stores.

We do not have any information regarding the specimen, as far as the excavations records are concerned (stratigraphy, laying, etc.), nor about the subsequent cleaning and consolidation processes. However, a simple visual analysis allows us to state that the specimen underwent a partial carbonisation, which has changed its original colour. The specimen was also apparently cleaned rather hastily, so that the lake silt deposit has not been completely removed. Afterwards, to avoid collapsing of its texture, the fragment of basketry was treated with an unknown consolidant resin which induced a gleaming aspect and an unnatural stiffness to the fragment.

The fragment is a specimen of stake-and-strand basketry (manufact measure: length $267 \mathrm{~mm}$; width $100 \mathrm{~mm}$; thickness $18.1-28.2 \mathrm{~mm}$ ) [1]. When compared to other basketry finds from same site of Fiavè-Carera [2], it could be located between the end of the Early Bronze Age and the end of the Middle Bronze Age (XVI-XIV C. BC).

The fragment was found in the peat bog of Fiavè just outside of Giudicaria valleys, in the South-west of Trentino. It is 


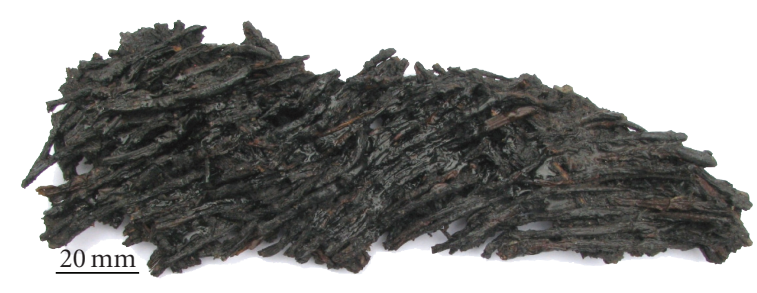

FIGURE 1: Image of the fragment of stake-and-strand basketry recovered from the prehistoric lake dwelling site of Fiavè-Carera (Trento, Italy).

a wide marshy area situated south of the modern village of Fiavè at $645 \mathrm{~m}$ a.s.l. which has occupied the basin of an ancient barrage lake of post-glacial origin, disappeared because of the progressive growth of peat-moss.

The first archaeological findings in the marsh of Fiavè took place in the context of to peat digging in the second half of the XIX C. Systematic excavations were carried out between 1969 and 1979 [3]; later, since 1981, there followed successive interdisciplinary surveys [4]. The good state of preservation of the settlement structures and material culture, with perishable materials like textiles and basketry artefacts, as well as the overall available stratigraphic series of the Bronze Age in the Southern Alps, support the point that Fiavè is one of the most important peat-bog sites of the whole of Italy.

The research activity reported in this paper is devoted to the use of laser cleaning to remove, after 40 years, the consolidant resin without damaging the original artefact. In addition, we will try to determine the raw material of the object in hand.

\section{EXPERIMENTAL METHODS}

Several pieces of the artefact previously described have been investigated. These pieces have been extracted from the archaeological find by cutting. The samples have a cylindrical geometry, with a 3-4 mm diameter.

Before starting the cleaning process with laser pulses (UV laser), a few preliminary investigations with Infrared Spectroscopy, Scanning Electron Microscopy, and Energy Dispersive Spectroscopy (FTIR, SEM, and EDS ${ }^{1}$ ) were made on the surface of basketry in order to obtain some information on composition and atomic bondings of the unknown resin. The irradiation source was a $\mathrm{KrF}$ excimer laser with a wavelength of $248 \mathrm{~nm}$ and a pulse duration of 20 nanoseconds. The repetition rate of the pulses was kept constant at $10 \mathrm{~Hz}$ to avoid excessive heating of the samples. All samples have been irradiated by using a special mask, with a circular hole ( $8 \mathrm{~mm}$ diameter), and by selecting a uniform beam profile.

\footnotetext{
${ }^{1}$ FTIR (Bruker Equinox 55); SEM (conventional SEM, JEOL JSM 6300. Samples were covered with a $20 \mathrm{~nm}$ carbon film); EDS (Noran Instruments, Voyager)
}

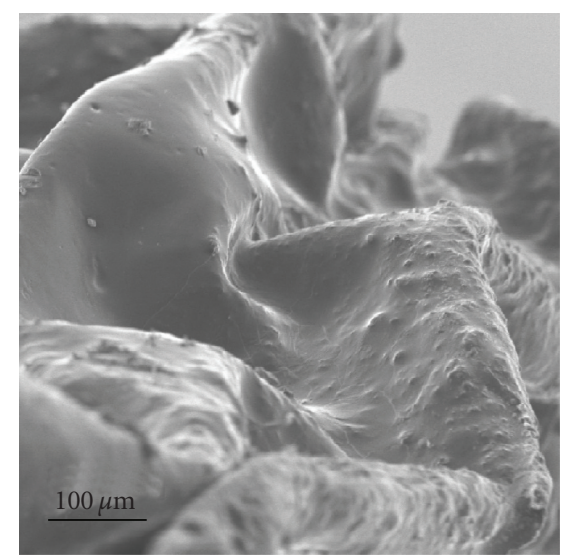

Figure 2: Particular of the sample. It is possible to see the complex morphology of the investigated surface.

The beam and the sample were always at rest during the irradiation process.

By looking at our previous results obtained on vegetable samples [5], the first guess energy densities have been fixed at 600,1000 , and $1400 \mathrm{~mJ} / \mathrm{cm}^{2}$. The number of pulses is strictly dependent on the thickness of the material to be removed: the organic substances deposited on the surface of the present wood samples are characterized by drastically variable thickness. Therefore, the laser irradiation sessions have been interrupted several times and SEM analyses were made in order to test the conditions of the irradiated area. Laser parameters are then chosen to completely remove the consolidant without damaging the wood surface. The number of pulses was in the range between some tens and some thousands, depending on the energy density and on the layer thickness to be removed. In order to extend the cleaning effects to larger area and better match both the cylindrical geometry of the sample and the irregular surface morphology (Figure 2), the samples have been rotated around their main axis. The total angle rotation was $120^{\circ}$, subdivided in five steps of $30^{\circ}$.

\section{RESULTS AND DISCUSSION}

FTIR, EDS, and SEM analyses have been performed in order to establish the kind of resin that covers the manufact surface. The surface of the manufact and the fibres, which have been used by prehistoric craftsman to prepare the object, appeared rounded, shiny, and covered by a sort of translucent substance (Figure 3). With EDS analysis, we determined that carbon and oxygen are the main components of this substance. Small amounts of aluminium, silicon, sulphur, chlorine, and calcium have been detected.

The most common substances used in current consolidation of prehistoric basketry are reported in the literature. However, in our case, we did not have records to identify the utilized consolidants. FTIR analyses have been performed on some of the most probable consolidant resins used in 


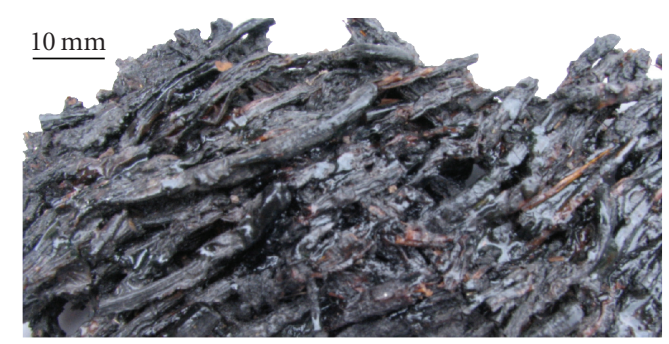

Figure 3: Particular of the manufact surface. The presence of consolidant, round off the surface, makes it shiny.

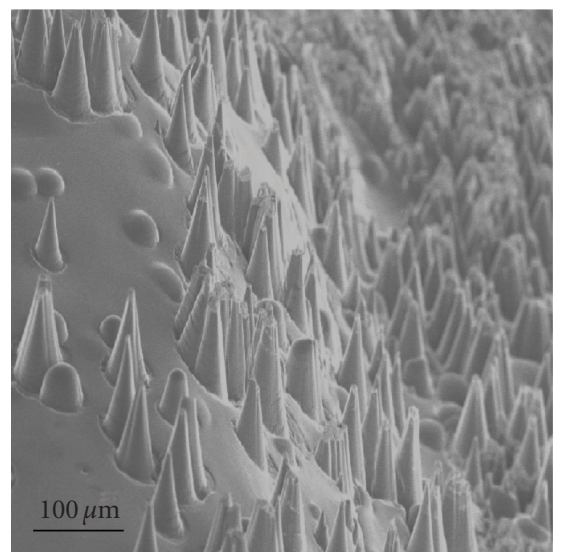

FIGURE 4: Cones formed on the consolidant surface at low laser energy density $\left(600 \mathrm{~mJ} / \mathrm{cm}^{2}, 500\right.$ pulses $)$.

the museum by restorer in 1970s (organic resin: Turpentine; synthetic resins: Paraloid B72, Primal, and Araldite): no one matched reasonably with FTIR data acquired from the unknown consolidant under investigation. We may only conclude that there is an overall similarity with resin spectra.

To investigate the interaction effects between laser and consolidant $[6,7]$, three small pieces have been detached from the manufact. These samples have been irradiated with laser pulses at different energy densities and the resulting effects have been analysed by SEM.

For low energy density $\left(600 \mathrm{~mJ} / \mathrm{cm}^{2}\right)$, the main result is the change in the surface morphology, which means the formation of a large number of cones (Figure 4). The size of these cones increases with the number of pulses; the same also occurs for their number until it reaches a saturation value after which only cones ablation is appreciable. The appearance of the cones on the surface is probably due to a well known thermal mechanism induced by laser irradiation on polymer surface [8]. The strong absorption of the laser pulse, below the energy threshold for macroscopic ablation, leads to a very fast heating of the surface coating followed by its thermal expansion; heating rates are estimated on the order of $10^{11} \mathrm{~K} / \mathrm{s}$. In such a condition, a portion of polymer, because

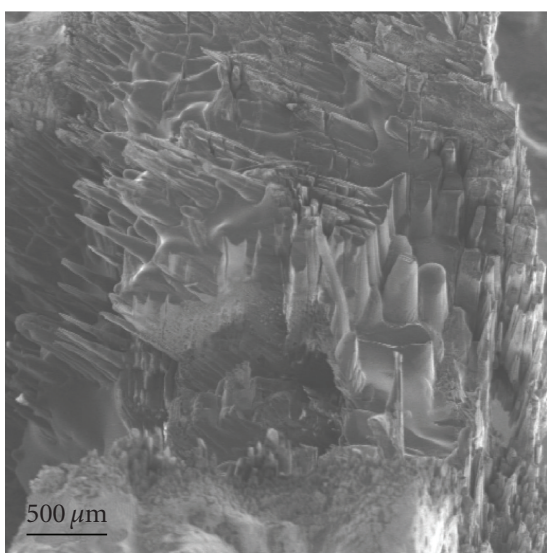

Figure 5: Different cone orientation because of sample tilting $\left(1000 \mathrm{~mJ} / \mathrm{cm}^{2}, 2000\right.$ pulses perpendicular to the surface and 500 pulses each at three different tilt angle, see experimental methods).

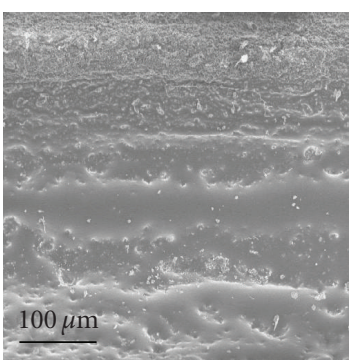

(a)

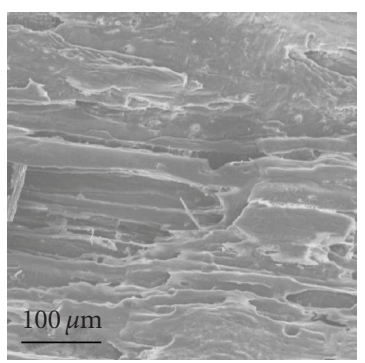

(b)
Figure 6: Consolidated surface (a) before and (b) after high energy density laser irradiation $\left(1200 \mathrm{~mJ} / \mathrm{cm}^{2}, 50\right.$ pulses at different tilt angles).

of the induced thermal stresses, blows out: the final results are therefore structures (cones) expanding in the normal direction to the target surface. Removal of the previous cones has been observed, along with formation of new reoriented cones (Figure 5), by irradiating the tilted sample.

For high energy density $\left(1200 \mathrm{~mJ} / \mathrm{cm}^{2}\right)$, a very efficient consolidant removal has been observed (Figure 6). The number of irradiation pulses should be dependent on the consolidant thickness that unfortunately is scarcely uniform; therefore, a number of pulses can impinge on the wood itself, causing some alteration.

Moreover, it was established that an energy density of about $1000 \mathrm{~mJ} / \mathrm{cm}^{2}$ marks the threshold between cone formation and consolidant removal.

In a second step, we tried to identify the wood used to prepare the manufact. In the current literature, few species of wood are reported, used by prehistoric craftsmen to prepare basketry: Cornus mas, Corylus avellenana, Salix alba, and Viburnum lantana [2].

Despite of the degradation conditions, due to the age of the find and of its environmental lying condition, it was 


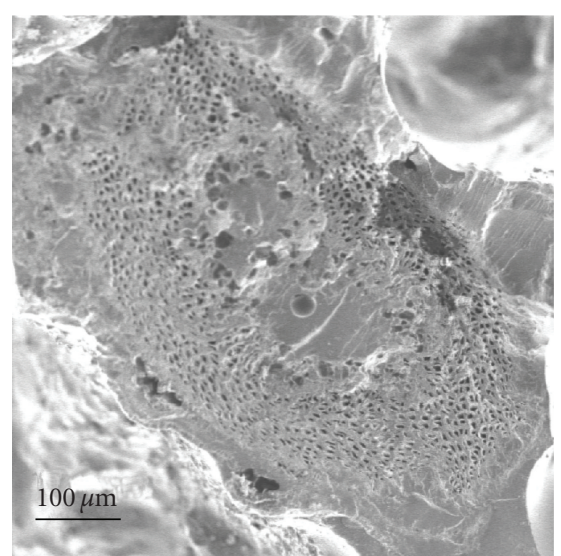

Figure 7: Cross-section of the sample.

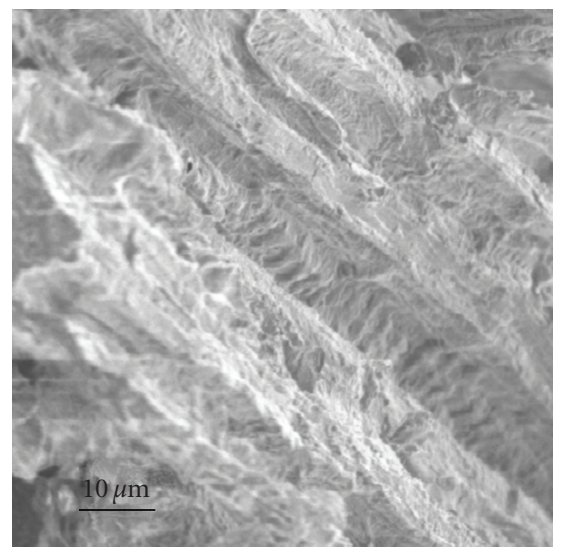

FIgURE 8: Longitudinal-section of the sample.

still possible to identify specific features that help in qualifying the wood. Indeed, as it can be seen in the cross-section (Figure 7), the sample has a diffuse-porosity with average size of pores of about $30 \mu \mathrm{m}$ and pores uniformly distributed into the annual growth ring. It was also possible to exclude the presence of multilayered pith rays [9]. Concerning the longitudinal section (Figure 8), we recognized some traces of scaliform perforations.

By combining all these findings, we conclude that the most probable wood, used to make the archaeological basketry, could be Viburnum lantana. This is also compatible with literature data.

\section{CONCLUSIONS}

The present study on laser cleaning of a prehistoric manufact provides some preliminary interesting results that certainly deserve further investigation.

The analyses have not been able to identify the consolidant materials used to cover the archaeological find.
Laser irradiation seems to be a promising way to clean organic finds, but some points should be further investigated, as below specified.

(i) Irregular surface morphology: the beam energy density impinging on the sample surface depends on the morphology of the surface: the presence of peaks and valleys could screen some areas to laser beam.

(ii) Nonuniformity of the consolidant thickness: this makes difficult to have a uniform cleaning of the sample because it would require different number of pulses in the surface area interested by a single spot. Too many pulses might damage the substrate where the consolidant thickness is smaller.

The first problem could be partially solved by systematically changing the sample orientation. Furthermore, the tilting has a relevant effect on final cones configuration. Indeed cones are ablated, reoriented, and reduced in their number.

To solve the second problem, a small interaction area should be interested along with a feedback system. This system could analyse in real time the irradiated area and stop the irradiation when cleaning is attained in the selected area.

\section{ACKNOWLEDGMENTS}

The authors wish to thank D. Avi (University of Trento) for FTIR analysis and discussion and G. Kezich (Director of the Museum of San Michele all'Adige) for supporting the research activity.

\section{REFERENCES}

[1] W. Wendrich, Who is Afraid of Basketry: A Guide to Recording Basketry and Cordage for Archaeologists and Ethnographers, CNWS, Leiden University, Leiden, The Netherlands, 1991.

[2] R. Perini, "Scavi archeologici nella zona palafitticola di FiavèCarera. Parte II: campagne 1969-1976, resti della cultura materiale: metallo, osso, litica, legno," 1987, PSAT 9.

[3] R. Perini, "Scavi archeologici nella zona palafitticola di FiavèCarera. Parte I: campagne 1969-1976, situazione dei depositi e dei resti strutturali," 1984, PSAT 8.

[4] J. L. Brochier, P. Corboud, F. Marzatico, R. Perini, C. Pugin, and A. M. Rachoud-Schneider, "Gli insediamenti preistorici dell'antico lago di Fiavè nelle Giudicarie, strategia di studio globale di un sito in ambiente chiuso," Archeoalp: Archeologia delle Alpi, vol. 1, pp. 127-144, 1993.

[5] R. Belli, A. Miotello, P. Mosaner, and L. Toniutti, "Laser cleaning of artificially aged textiles," Applied Physics A: Materials Science and Processing, vol. 83, no. 4, pp. 651-655, 2006.

[6] L. D. Laude, D. Martinez, Cl. Dicara, Fr. Hanus, and K. Kolev, "The ablation of polymers under excimer laser irradiation: the physics of the process and the polymer structure," Nuclear Instruments and Methods in Physics Research, Section B: Beam Interactions with Materials and Atoms, vol. 185, no. 1-4, pp. 147$155,2001$.

[7] H. Horn, S. Beil, D. A. Wesner, R. Weichenhain, and E. W. Kreutz, "Excimer laser pretreatment and metallization of polymers," Nuclear Instruments and Methods in Physics Research, Section B: Beam Interactions with Materials and Atoms, vol. 151, no. 1-4, pp. 279-284, 1999. 
[8] R. Kelly, A. Miotello, B. Braren, A. Gupta, and K. Casey, "Primary and secondary mechanisms in laser-pulse sputtering," Nuclear Instruments and Methods in Physics Research Section B: Beam Interactions with Materials and Atoms, vol. 65, no. 1-4, pp. 187-199, 1992.

[9] F. H. Schweingruber, Anatomy of European Woods: An Atlas Fort He Identification of European Trees, Shrubs and Dwarf Shrubs [Anatomie Europäischer Hölzer: Ein Atlas zur Bestimmung Europäischer Baum-, Strauch- und Zwergstrauchhölzer], Haupt, Bern, Germany, 1990. 